\title{
Eco-systematic restoration: a model community at Salton Sea
}

\author{
I. Mazzoleni \& Team (P. Ra, A. Barthakur, S. Price, V. Zajfen, \\ S. Varma, B. Mehlomakulu, H. Portillo, S. Milner \& S. Proudian) \\ SCI-Arc, Los Angeles, USA
}

\begin{abstract}
The traditional model of growth is a zero sum game with discrete land use typologies, where growth in one area can only happen at the expense of another. Our primary motivation in developing this model systemic community is to provide a paradigmatic shift in accommodating growth: by harnessing and integrating systems that are cyclical in nature and time, the community will rejuvenate and heal the surrounding ecology with every cycle rather than eroding it over time.

The approach is holistic, in that we consider interrelationships between all processes fundamental to sustaining life and preserving nature: water and energy cycles, agriculture and seasonality, production and the exchange economy, as well as social needs of a multi-generational community. Furthermore, our strategy is hinged on the notion of restoring scarred landscapes, making them givers of life, and enhancing their integration into the surrounding ecology and life.

The process of healing is emphasized by a symbiotic relationship between the community and the natural environment. The goal is to create a community that has a 0 net impact on emission, waste, energy and water while reducing the Sea salinity level and maintaining the ecosystem it supports.

The paper will focus on the illustration of the model community as case study of not only sustainable architecture but as example of a biomimetic approach to design inspired by natural eco-systems.
\end{abstract}

Keywords: eco-system, biomimicry, sustainability, architecture, Salton Sea. 


\section{Introduction}

The traditional model of growth is a 'zero sum' game with discrete land use typologies, where growth in one can only happen at the expense of another. Our primary motivation in developing a systemic community is to provide a paradigm shift in accommodating growth - by capturing and integrating systems that are cyclical in nature and time, with each cycle rejuvenating and healing the surrounding ecology rather than eroding it over time.

The approach is holistic, in that we consider interrelationships between all processes fundamental to sustaining life and preserving nature - water and energy cycles, agriculture and seasonality, production and the exchange economy, as well as social needs of a multi-generational community. Our strategy, however, is hinged on the notion of restoring scarred landscapes, making them givers of life, and enhancing their integration into the surrounding ecology and life.

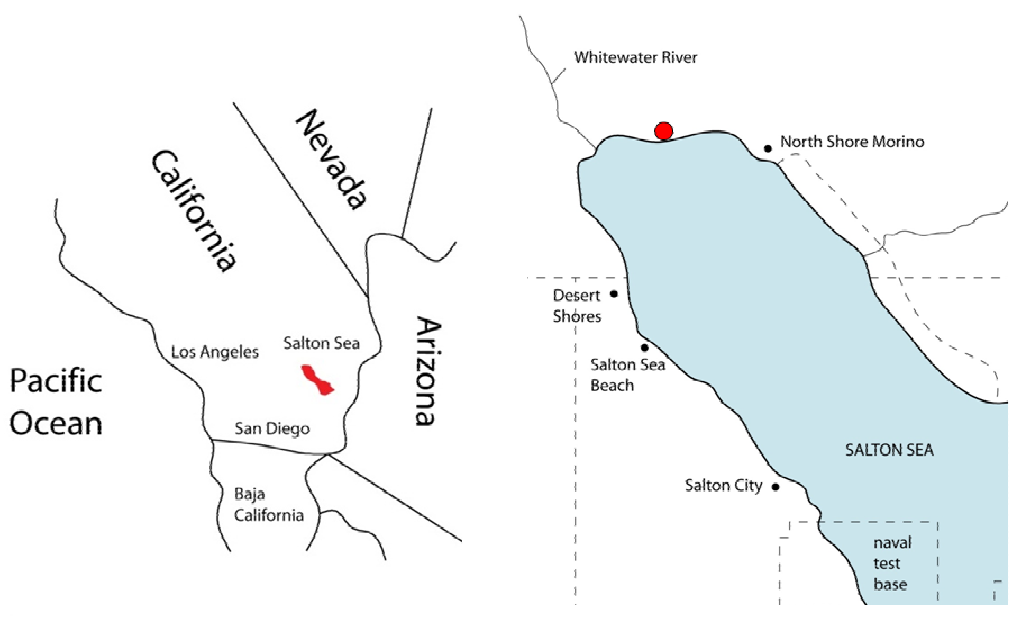

Figure 1: $\quad$ Map of Salton Sea.

\section{The site}

Our project site is located on the northern bank of the Salton Sea. Contrary to its name, the Salton Sea is the largest lake in California and is located approximately 130 miles southeast of Downtown Los Angeles, and about 35 miles southeast of Palm Springs. It is 35 miles by 15 miles across with an average depth of 29.9 feet and 51 feet at its deepest, and has over 100 miles of shoreline; it is located 228 feet below sea level. It is essentially a basin that had filled up with occasional flooding of the Colorado River, but now gets constantly replenished by the agricultural runoff from the area surrounding it. The lack of any outlets makes it a very unstable ecosystem with rising salinity and increasing toxicity. 


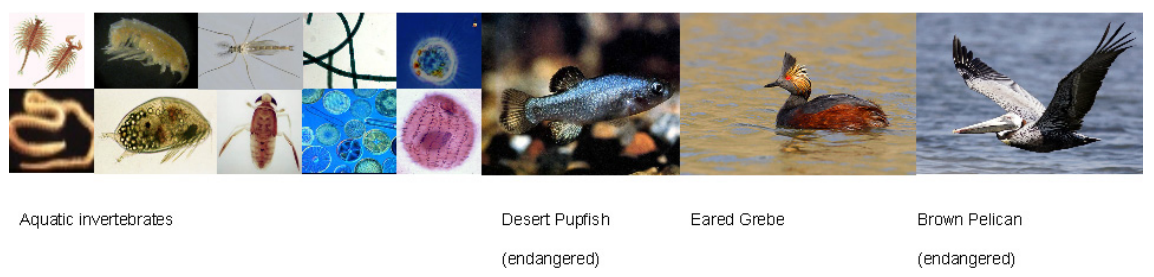

Agricultural run-off causes high

salinity and over-abundance of nutrients, leading to algal blooms and fish die offs
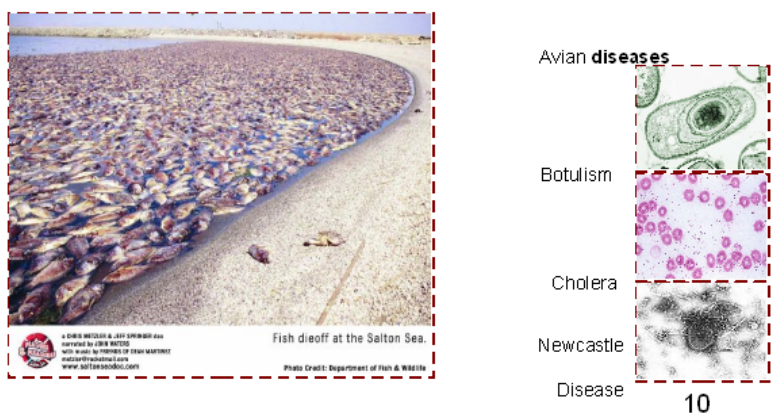

Figure 2: $\quad$ Salton Sea eco-systems.

\section{Strategy of occupation}

The process of healing is emphasized by a symbiotic relationship between the community and the natural environment in and around Salton Sea. Key objectives are to reduce the Sea's salinity levels, provide alternative models of agriculture, and maintain the ecosystem it supports. We have incorporated a number of strategies that emphasize this symbiotic relationship such as biofuel producing algae farms, which have a dual role as an energy source as well as an environmental cleanser. Nature sensitive agricultural practices and crop types provide food provide a food source and economic benefits to the community while eliminating chemical runoffs into the Sea. Passive energy strategies such as the heat sink and solar ponds use the Sea's mass and salinity to the advantage of the community.

The 3200 acres of land considered in this project is part of an ecological restoration effort to heal the site and create life-sustaining conditions, appropriate for the desert environment. The chosen site is already occupied and developed. We are re-occupying it with the smallest possible building footprint, creating clusters of buildings organized around public spaces and productive areas, using 
nature as our mentor. The goal is to create a community that does have a net 0 impact on emission, waste, energy and water.

We feel that our approach can be a model in the adjacent desert communities that have practiced unsustainable living and agriculture for more than 50 years; and possibly, over the next 25 years Salton Sea's North Bank could be renewed by:

a) Rehabilitation of agricultural land, and conversion to "slow" agriculture.

b) "Zero Impact" growth with additional housing as an expansion to our community or in creation of similar ones in the region.

c) Clean production and creative factories attracting people to the area and incubating innovative environment sensitive industries.

d) Increasing 0 impact energy production as conventional agricultural uses are replaced by the suggested agricultural practices and crops.

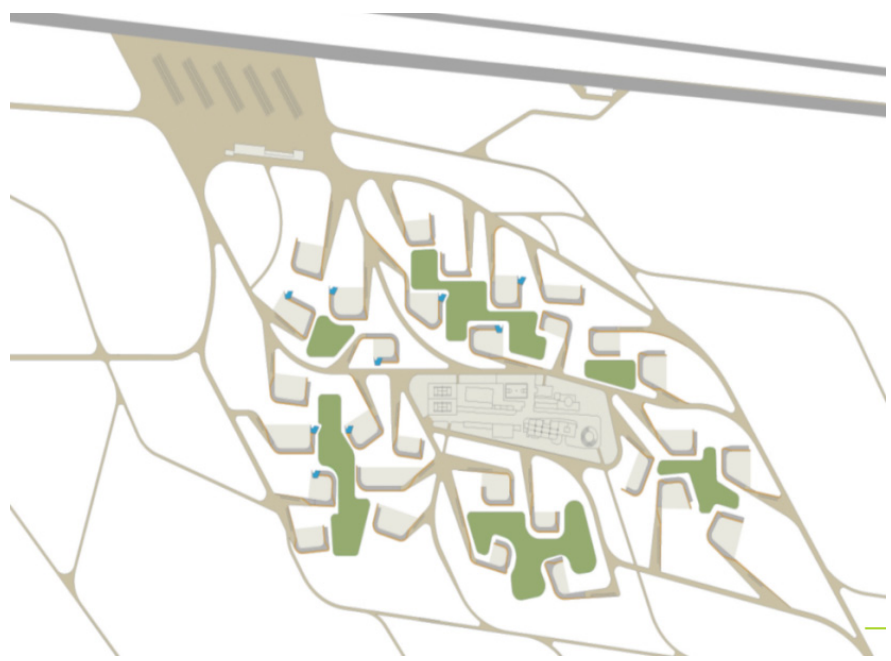

Figure 3: Site plan of a 1000 people model community.

\section{Community design}

We think that the process of architecture is a plan to manage a built object's life, and we address architecture as a process for construction as well as dismantling.

We re-occupy the site and inject infrastructure to support production as we feel that the picture of a sustainable community is incomplete if all aspects of the community living not taken into account. Besides "dwelling", fulfilling a community's productivity and economic needs, and social needs, within a sustainable framework is of utmost importance. 
The land is reconfigured with uses within its carrying capacity, in a way that it is engaged and not exploited. The residential component includes a variety of unit sizes and types allowing a multigenerational community to flourish. Several communal spaces are linked to the residential dwellings, and others to the entire community allowing for multiple public activities. Each design element serves multiple community objectives - similar to any living organism where all of the specialized parts collaborate for communal well being.

The community's current capacity is for 1000 people as designed, but it allows for future growth, in response to local and regional pressures.

Solar energy, water conservation strategies, non-emissive materials and earth embankments are introduced as design considerations, to reduce the energy input of the inhabitable space, and provide energy conservation in residential housing.

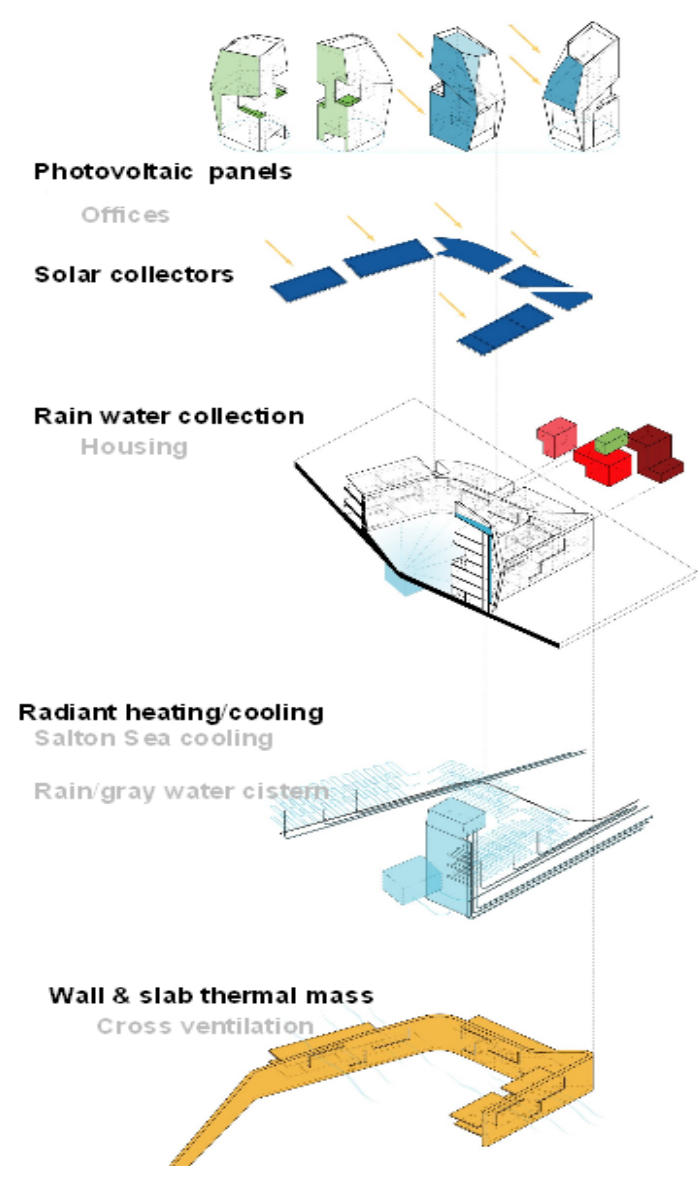

Figure 4: Building systems breakdown. 
The earth houses and water towers are characterized by their thermal stability and energy efficiency. Several passive strategies, integrated with low consuming active systems described below are implemented:

\section{Passive systems}

The key to reducing building energy consumption is to take advantage of the benefits that can be provided by the sites natural environment. Creating a synergy between the systems, building and the site recreates the potential to eliminate active systems in some cases and significantly reduce the size of active systems in others.

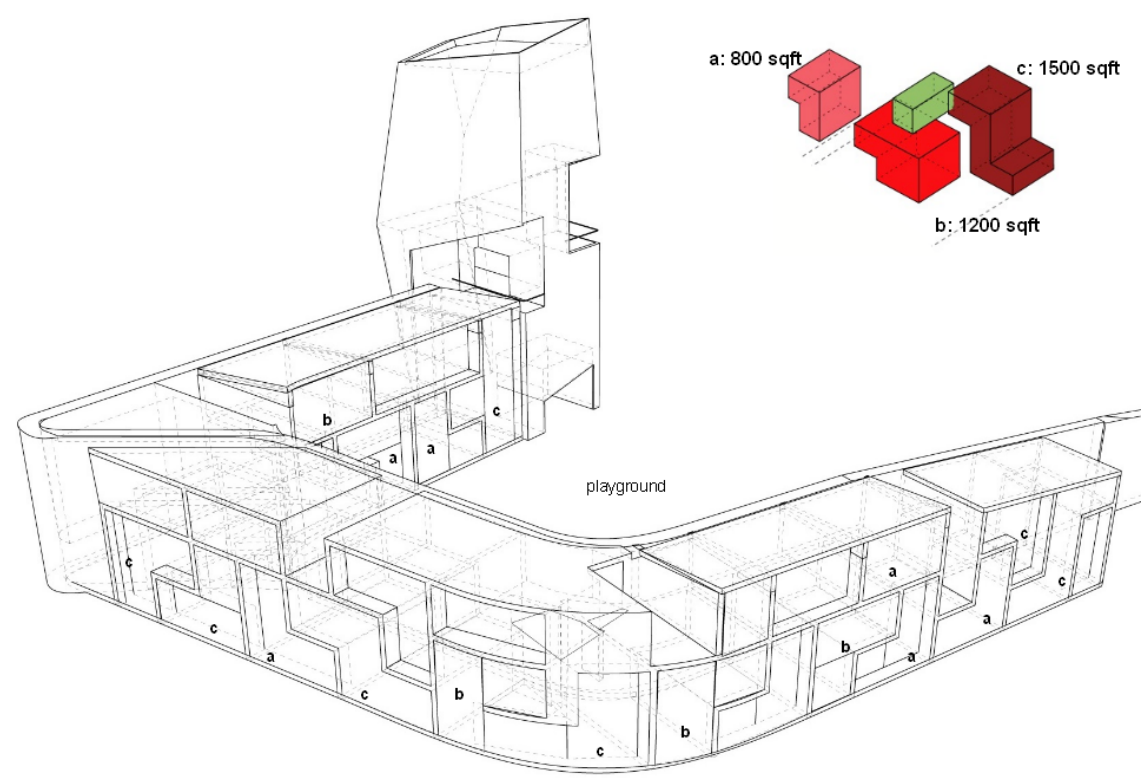

Figure 5: Housing units variation and office tower.

The key to the Salton Sea climate is to minimize the impact of the high summer temperatures and solar heat gains, take advantage of natural wind currents, and harness what rain is available on the site (what about harnessing solar heat?). Fortunately for the Salton Sea, there is limited humidity to be controlled so natural ventilation can be utilized during most of the year.

The narrow profile of the building is conducive to creating cross flow natural ventilation during temperate days, and cool evenings and nights. On the single buried levels, a high space provides for high level openings to create a cross flow of air providing natural ventilation to all levels.

The passive systems of the building buffer the interior from the extreme summer heat. This is accomplished by adding additional mass to the building in 
the form of earth walls, and water columns. The mass walls on the lower portion of the building protect the south orientation, and then dives through the building to protect the west orientation where necessary. The mass on the south and west sides provide a shield to absorb heat to be rejected in the cooler evenings. This strategy also works in cold climates where the heat from the day is absorbed and rejected to the interiors during the colder nights. The towers are wrapped with a skin of water, both recycled grey water, and rejected water from the cooling system for usage inside the buildings. Grey water captured from rain fall, showers, and sinks to be used later for irrigation, flushing toilets and washing machines. Cooling water stored in the towers is sprayed across the roof tops and cooled using night sky radiation to reduce the temperature. The mass from the water serves the same purpose as the rammed earth walls to absorb heat to be reject to the outside during cooler periods.

Openings on the south and west orientations are limited to reduce direct solar radiation during peak summer months, while the openings on the north and east elevations provide diffuse natural daylight reducing the need for artificial lighting. Glazing will provide solar protection while still allowing sufficient levels of daylight to enter into the space.

While passive strategies gain much to reduce the heat gain (or heat loss) into the space, in all but the most temperate of climates active cooling or heating is required to maintain the space temperatures within acceptable comfort levels.

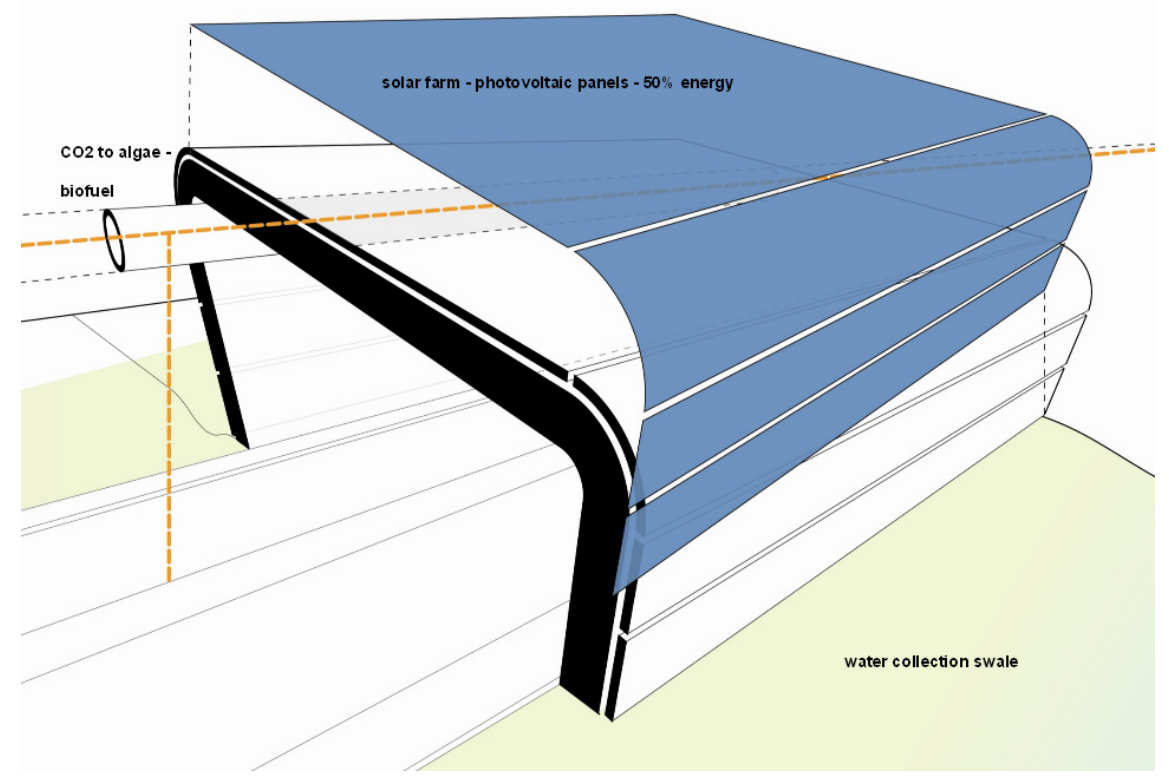

Figure 6: $\quad \mathrm{Co} 2$ collection. 


\section{Active and generative systems}

While water is an increasingly scarce resource around the world, the use of hydronic systems to directly provide cooling to the space are significantly more efficient in reducing space conditioning systems while at the same time improve the quality of occupant comfort. Hydronic radiant systems are located in the building slabs as well as portions of the thermal mass wall. The radiant systems located in the slabs are exposed not only to the spaces above, but also those below improving the overall efficiency of the system. The radiant tubes located in the mass wall not only serve to cool the space, but also provide a means of cooling the mass at night via night sky radiation.

The central heating and cooling system utilizes a system of roof-mounted tubes to absorb solar radiation during the day to generate hot water, and uses the cold night sky to reject heat at night.

The central cooling system provides cooled water to the radiant systems via a dual service night sky radiation system, and the heat reservoir provided by the Salton Sea. Exposing water to the very low temperature of the night sky cools the water to a temperature that is usable by the radiant floor system. For this particular location, the size of the Salton Sea serves as a sufficiently large heat sink to reject heat without endangering the sea's ecosystem.

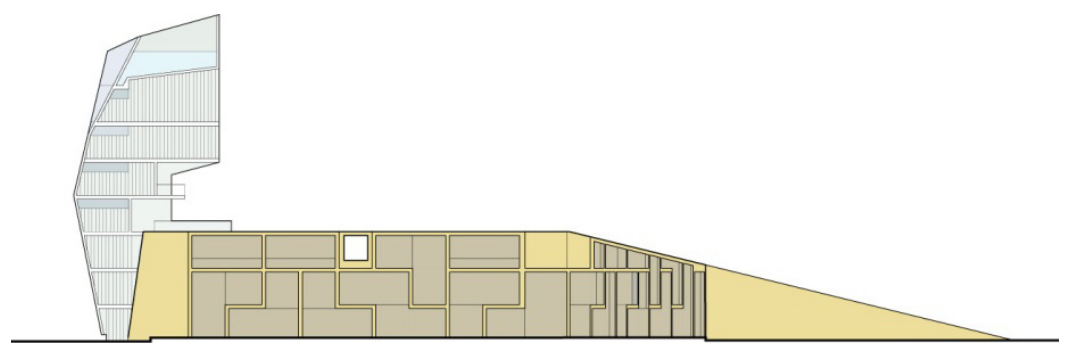

Figure 7: Elevation of housing unit and office tower.

The central heating system operates off of gas extracted from the algae farms to operate boilers which circulate water through the building. To supplement heating demands, the solar collectors used for night sky radiation are used during the day to meet the demands of domestic hot water systems.

All energy needed by the community will be generated within the community. Solar and wind technologies will provide all required electricity for residential consumption. The residential energy system design includes significant over capacity. The extra capacity will be used to charge emergency batteries. The extra energy will be sold into the grid to export emissions free electricity for consumption outside the community. 


\section{The systematic community}

The site in Salton Sea transcends its limits, acting as a geographical attractor of regional interest. The existing highway 111, connects manufacturing centers along the Mexican border not only to the Los Angeles region but also to a transportation network serving the entire United States. This existing infrastructure is considered to be a means of regional access for all visitors. An inter-modal parking lot will allow the exchange to a non-emittive transportation system to travel within the community.

The new community will integrate several uses: from the creative offices located in the towers, an eco-lodge to support the Salton Sea lost tourist nature, to the research field station. The town center includes services integral to community life: a school, sport center, multipurpose open theater, markets and public offices. Growth over time will integrate additional uses - avoiding monofunctionality- and additional visitors.

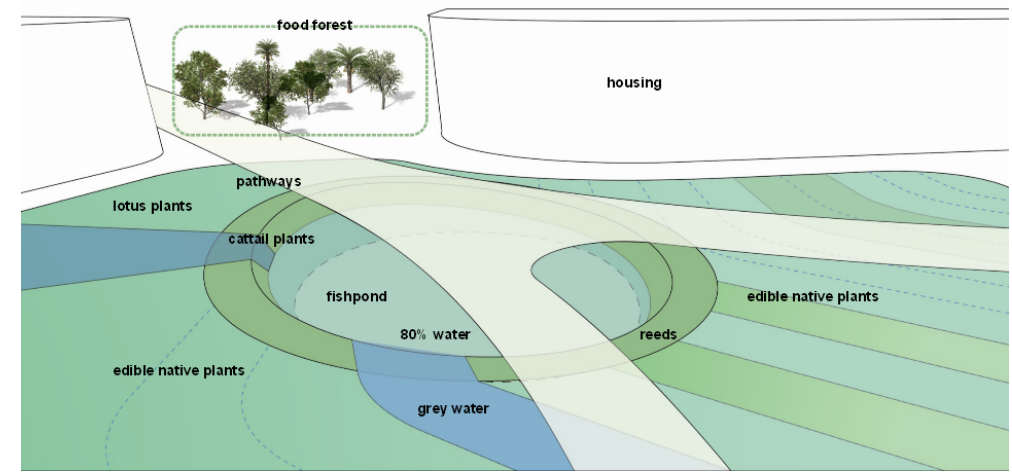

Figure 8: Community and grey water treatment garden.

The beach park connects to the existing state park south of our site, protecting the natural lake edge. The food forest provides a food source as well as a recreational area of the community.

The community is organized in 6 clusters, which rotate around a community garden. Each individual building has a central playground to allow children and adults to meet, interact and play.

The office towers are the center of activities and provide a vivid exchanging environment, which contribute to create a higher intensity of social relations.

Eliminating the commuting to the not far Los Angeles and San Diego areas while providing a rich and vibrant cultural end entrepreneurial environment is the aim of this community based on innovation and research inspired by nature. 


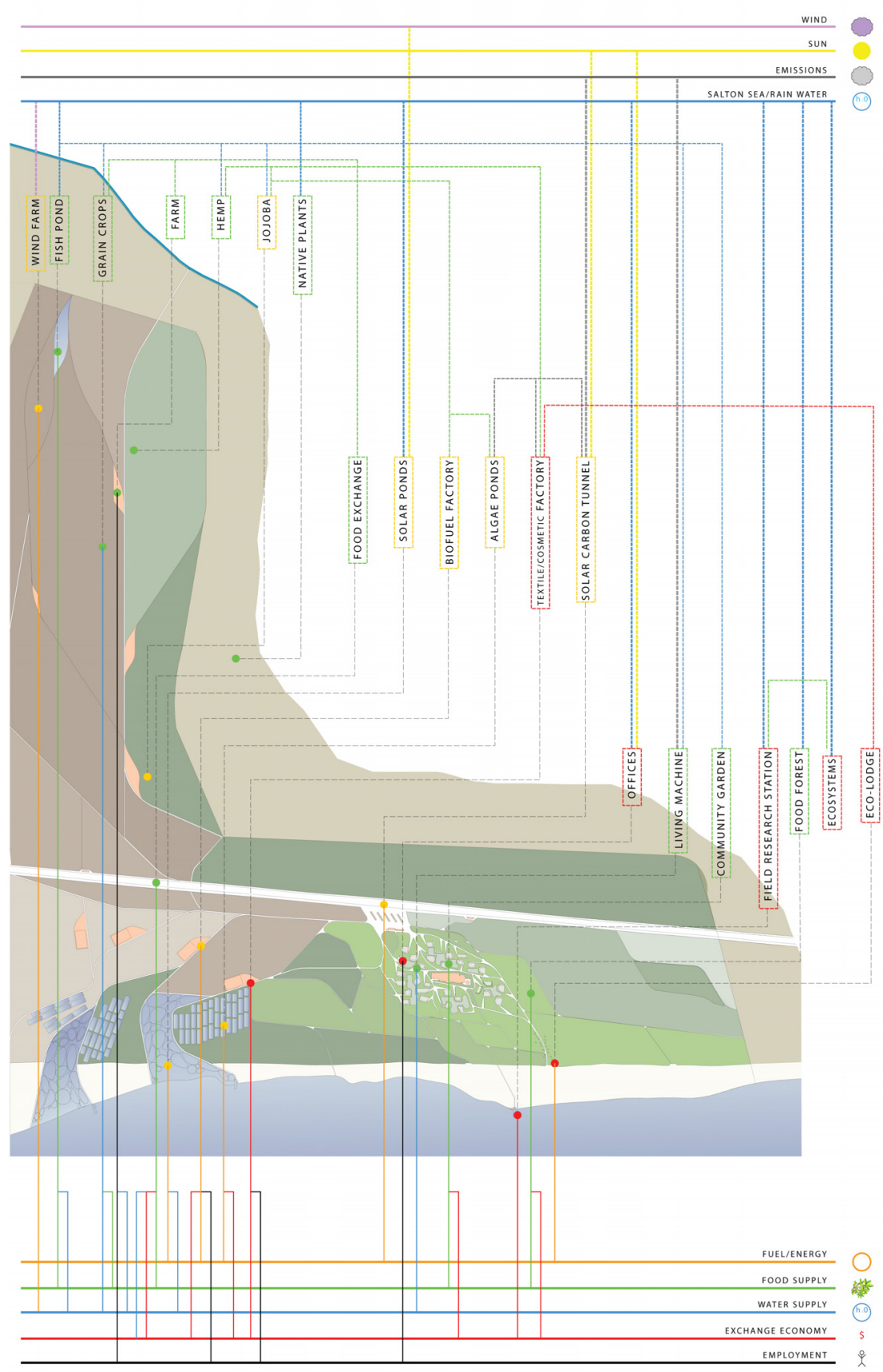

Figure 9: Integrated system. 


\section{Conclusions}

The paper illustrates how our individual ecological footprint is much larger then we are aware off. The project designs a community not only composed of the housing and the public spaces around it, but that incorporates all the other elements necessary to feed, employ and create an exchange economy with the surrounding communities. This interconnectivity does not produce waste, but creates a chain of usage. This phenomenon although common in nature is still a novelty in architecture and exploring its potentials has been the team's challenge.

In Working with constant feed back loops nature has learned how to adapt and survive. This community similarly learns and evolves based on the interaction between all entities. The farmlands, clean factories, algae farms, solar ponds, are a productive eco-system that uses land, air, sun, and water as fundamental elements of life without exploiting but allowing the natural cycles to function in balance. With this process the scarred land of Salton Sea will have a chance to produce a new healthy life for all its inhabitants: flora, fauna and human kind and finally synchronize with nature's rhythm of life.

\section{Reference}

[1] Benyus J.M., Biomimicry, Innovation Inspired by Nature, Perennail, 2202

[2] Von Friesch K., Animal Architecture, Harcourt Brace Jovanovich, 1974

[3] Blumberg M.S., Body Heat, Harvard University Press, 2002

[4] McDonough W., Braungart M., Cradle to Cradle, North Point Press, 2002

[5] Pearce P., Structure in Nature is a Strategy for Design, The MIT Press, 1990

[6] Bar-Cohen Y., Biomimetics Biologically Inspired Technologies, Taylor \& Francis, 2006

[7] Beukers A. \& Van Hinte E., Lightness, 010 Publishers, 1999

[8] Brown G.Z., Sun, Wind, Light: Architectural Design Strategies, John Wiley and Sons, 2001

[9] Steffen A., WorldChanging: A User's Guide for the $21^{\text {st }}$ Century, 2006

[10] Siegrist R.L., Management of Residential Greywater, Department of Civil and Environmental Engineering

[11] Mollison B., Permaculture a Designers Manual, Tagari Publications, 1997

[12] Stauffer N., Algae System Transforms Greenhouse Emissions into green fuel, MIT Energy Research Council

[13] Salton Sea, Ecosystem Restoration Program, Final Environmental Impact Report, California Resource Agency, 2006

[14] The Salton Sea Authority, hhtp://www.saltonsea.ca.gov 